\title{
Active Transport of 3-0-Methyl-Glucose by the Small Intestine in Chronically Catheterized Rats
}

\author{
Michael R. Uhing and Robert E. Kimura \\ Division of Neonatology, Department of Pediatrics, Rush Medical College, Rush-Presbyterian-St. Luke's Medical Center, \\ Chicago, Illinois 60612
}

\begin{abstract}
A method is described for determining the fraction of intestinal 3- $O$-methyl-glucose (30MG) absorption that occurs by active transport in chronically catheterized rats without the influence of anesthesia or surgical bowel manipulation. That fraction was determined by simultaneously measuring portal venous-aortic blood concentration gradients $(\Delta C)$ of 3 $O$-methyl-glucose (30MG) and L-glucose, metabolically inert analogues of D-glucose. $30 \mathrm{MG}$ is actively and passively absorbed by the same mechanisms as D-glucose. L-glucose is only passively absorbed. The fraction of 30MG that is actively transported was calculated from the difference between 30MG and L-glucose absorption, divided by total 30MG absorption. We found that more than 94\% of 3-O. methyl-glucose is absorbed by active transport when luminal concentrations range from 50 to $400 \mathrm{mM}$. We conclude that in unrestrained, unanesthetized chronically catheterized rats, most 30MG is actively absorbed by the intestine even at high luminal concentrations. (J. Clin. Invest. 1995. 95:2799-2805.) Key words: intestinal absorption - biological transport • methylglucosides $\cdot$ glucose $\cdot$ permeability
\end{abstract}

\section{Introduction}

Previous studies of intestinal glucose absorption used models in which the intestine is acutely manipulated surgically either in vivo or during excision for in vitro experiments. Some of these studies claim that passive absorption of glucose by the intestine begins to exceed active transport at luminal glucose concentrations as low as $35-60 \mathrm{mM}(1-4)$. The primary in vivo method for studying intestinal glucose transport has been the measurement of the rate of disappearance of glucose from the perfusate of a luminally perfused isolated loop of intestine in an anesthetized, acutely laparotomized animal $(2,5-8)$. In some studies, the intestinal vasculature is also perfused (911). In vitro methods for studying intestinal glucose transport include everted sleeves of intestinal tissue $(4,12-14)$, isolation of membrane vesicles (15-18), and cell cultures (19).

Address correspondence Michael R. Uhing, Division of Neonatology, Department of Pediatrics, Rush Medical College, Rush-Presbyterian-St. Luke's Medical Center, 1653 W. Congress Parkway, Chicago, IL 60612. Phone: 312-942-6640; FAX: 312-942-4370.

Received for publication 24 October 1994 and in revised form 17 January 1995.

J. Clin. Invest.

(C) The American Society for Clinical Investigation, Inc. 0021-9738/95/06/2799/07 \$2.00

Volume 95, June 1995, 2799-2805
Surgical bowel manipulation and anesthesia have many potential effects on the intestine including alterations of the unstirred water layer (20), intestinal motility (21), intestinal blood flow (22), tissue hydrostatic pressure (23-25), mucosal integrity, and cellular energy levels (26). Therefore, it may not be appropriate to extrapolate the results obtained under these conditions to unanesthetized, nonlaparotomized animals (27). Using a chronically catheterized rat model, we showed that portal venous and aortic blood concentrations of glucose after a gastric bolus increased at a slower rate immediately postoperatively compared to subsequent measurements (28).

We developed a method to determine the fraction of intestinal 3-O-methyl-glucose (3OMG) ${ }^{1}$ absorption that occurs by active transport under physiologic conditions in chronically catheterized rats. Using our model, we are able to measure the portal venous and aortic blood concentrations of L-glucose and $30 \mathrm{MG}$ after their infusion into the duodenal lumen. Because L-glucose and 3OMG are not metabolized in the intestine, the rate of their appearance into the portal vein is equal to their rate of absorption from the intestinal lumen $(9,29,30)$. 3OMG is actively transported by the same sodium-dependent cotransporter as D-glucose with a similar $V_{\max }$ and $K_{\mathrm{m}}(15,31)$. In this paper, we show that L-glucose absorption is similar to passive $30 M G$ absorption. By comparing the relative net rate of appearance of 3OMG and L-glucose into the portal vein, we calculated the fraction of intestinal $30 \mathrm{MG}$ absorption that is active.

This method offers many advantages over previous methods. Intestinal function can be studied in unanesthetized, unrestrained animals in a nonfasting state without the influence of surgical bowel manipulation. Because we measure the portal venous-aortic concentration gradients of total glucose absorption and its passive component simultaneously, various factors that affect the absorption of both components equally ( such as the length of intestine exposed) do not change the relative fraction of total glucose absorption that is active. Each measurement of the relative contribution of passive and active transport can be performed in the same animal at the same time, thereby eliminating inter-animal and inter-experiment variability.

Using our chronically catheterized rat model without the influence of surgical bowel manipulation and anesthesia, we found that $>94 \%$ of intestinal 3OMG absorption occurs by active transport at luminal $30 \mathrm{OG}$ concentrations ranging from 50 to $400 \mathrm{mM}$.

In the accompanying paper, we confirm the findings of this paper using a different method to measure intestinal glucose

\footnotetext{
1. Abbreviations used in this paper: 3OMG, 3-O-methyl-glucose; $\mathrm{C}$, blood concentration; $\mathrm{F}_{\text {active }}$, fraction of total absorption that is active; $\mathrm{J}$, absorption rate; $K_{\mathrm{m}}$, Michaelis-Menten constant; PEG, polyethelene glycol; $V_{\max }$, maximum transport velocity; $\Delta \mathrm{C}$, portal venous-aortic blood concentration gradient.
} 
absorption in chronically catheterized rats and show that surgical bowel manipulation causes a $90 \%$ decrease in active glucose transport by the intestine (32). Thus, the higher fraction of glucose absorption occurring by active transport found in this study is because our experiments are performed under conditions that are not influenced by surgical bowel manipulation.

\section{Methods}

Animals. Male Sprague-Dawley rats weighing 250-400 grams were obtained from Charles River Breeding Laboratories (Wilmington, MA). The rats were maintained under a 10:14 h light:dark cycle. Water and chow (Agway Rat Mouse Hamster Chow 3000) were available ad libitum except for the $4 \mathrm{~h}$ before an experiment when the animals were NPO.

Chemicals. All nonradioactive chemicals and reagents were obtained from Sigma Chemical Co (St. Louis, MO). All radioactive isotopes were obtained from DuPont-New England Nuclear Research Products (Boston, MA).

Operative procedures. The aortic and duodenal catheters were made by inserting a $0.5-\mathrm{cm}$ tip of a 22 -gauge Insyte catheter (Becton Dickinson Vascular Access, Sandy, UT) into a 3-cm segment of silastic tubing (ID = 0.03"; Baxter, McGaw Park, IL). A 0.5-cm segment of PE60 tubing (Clay Adams, Parsippany, NJ) was inserted into the other end of the silastic tubing. The catheters were then placed over 22-gauge Insyte needles. The portal venous catheter was made by inserting a $0.5-$ $\mathrm{cm}$ segment of PE60 tubing over both ends of a 6-cm segment of silastic tubing. This catheter was placed over a 22 -gauge spinal needle.

The surgical procedure was performed under sterile conditions as previously described (28). Briefly, male Sprague-Dawley rats were anesthetized with ketamine $60 \mathrm{mg} / \mathrm{kg}$ and xylazine $1.0 \mathrm{mg} / \mathrm{kg} \mathrm{IM}$. The abdomen and back were shaved and washed with ethanol and Betadine. A midline vertical incision was made from the xyphoid process to the suprapubic region, and a 1-cm skin incision was made over the cervical vertebrae. The tubing from three 3.5" intermittent infusion sets (Abbott Laboratories, North Chicago, IL) from which the butterfly needles had been previously removed were pulled through the cervical incision to the abdominal incision, and flushed with $0.9 \%$ saline containing $10 \mathrm{U}$ heparin/ml. A vertical incision was then made in the abdominal wall, and the tubing introduced into the peritoneal cavity by making small punctures on the right side of the abdominal wall.

After retracting the intestines to the left onto sterile saline soaked gauze, the aortic catheter was introduced over the 22 gauge Insyte needle $\sim 0.5 \mathrm{~cm}$ into the aorta just distal to the renal arteries. The distal end of the catheter was inserted into one of the 3.5" infusion set tubings on the right side of the peritoneal cavity. The same procedure was used to introduce a catheter into the portal vein just proximal to the liver. Both catheters were secured with one drop of cyanoacrylate glue (Wonder Bond Plus, Borden Inc., Columbus, $\mathrm{OH}$ ).

After placement of the vascular catheters, the duodenal catheter was introduced over the 22-gauge Insyte needle $2-\mathrm{cm}$ proximal to the ligament of Trietz with the tip pointing distally and secured with a 5-O silk suture through the serosal layer of the intestine $0.25 \mathrm{~cm}$ proximal to the insertion site. An intermittent infusion set tubing was connected to the distal end of the catheter in the same manner as for the vascular catheters. The intestines were returned to the peritoneal cavity. The abdominal musculature and skin were closed in two layers with an interlocking stitch using 4-0 silk suture. To maintain catheter patency, the catheters were flushed daily with $0.35 \mathrm{ml}$ of $0.9 \% \mathrm{NaCl}$ containing $500 \mathrm{U} / \mathrm{ml}$ of heparin and $2.5 \mathrm{mg} / \mathrm{ml}$ of ampicillin.

Average weights of the rats preoperatively and on the fourth postoperative day were $284 \pm 32$ gms and $280 \pm 30$ gms, respectively (mean \pm SD). By the fourth postoperative day, all rats achieved at least $95 \%$ of their preoperative weight.

Measurement of portal venous and aortic blood concentrations of $\left[{ }^{3} \mathrm{H}\right]$ and $\left[{ }^{14} \mathrm{C}\right]$ after infusion of radiolabeled $\mathrm{L}$-glucose and $3 \mathrm{OMG}$ into the duodenum. Experiments were performed at least $4 \mathrm{~d}$ postoperatively. This time frame was chosen because the rats were gaining weight and had reached at least $95 \%$ of their preoperative weight, and because studies described in the accompanying paper showed that the effects of surgical bowel manipulation were no longer present at this time (32). The rats were NPO for $4 \mathrm{~h}$ before performing the studies.

In some rats, multiple experiments were performed. Since each experiment was performed at least $24 \mathrm{~h}$ apart and 3OMG and L-glucose are not metabolized, there was minimal accumulation of isotope in the rat. In addition, we calculated the fraction of active transport from the change in the blood concentrations of 3OMG and L-glucose as blood flows from the aorta into the portal vein and aorta and not on the absolute concentrations of L-glucose and 3OMG.

A $1.0 \mathrm{ml}$ bolus of 3OMG (either $50,100,200$, or $400 \mathrm{mM}$ ) containing tracer amounts of $\left[{ }^{14} \mathrm{C}\right] 3 \mathrm{OMG}(0.5-5.0 \mu \mathrm{Ci} / \mathrm{ml})$ and $\left[{ }^{3} \mathrm{H}\right] \mathrm{L}-$ glucose $(10 \mu \mathrm{Ci} / \mathrm{ml})$ was infused into the duodenum over $0.6 \mathrm{~min}$. After $\sim 30 \mathrm{~s}$, three simultaneous serial blood samples $(0.25 \mathrm{ml})$ were drawn from the aortic and portal venous catheters. Each sample was drawn over $5 \mathrm{~s}$, with all samples obtained over a 1-min period. The catheters were not flushed between samples.

Analytical methods. Blood samples were added to $0.3 \mathrm{ml}$ of $1.0 \mathrm{M}$ $\mathrm{HClO}_{4}$, and centrifuged for $5 \mathrm{~min}$ at $17,000 \mathrm{rpm}$ (Microfuge $\mathrm{E}^{\mathrm{TM}}$; Beckman Instruments, Palo Alto, CA). Duplicate 0.1-ml aliquots of the supernatant were then counted in $5 \mathrm{ml}$ of scintillation fluid (EcoLume ${ }^{\star}$, ICN, Costa Mesa, CA). The radioactivity was measured in a Mark V scintillation counter (model 5303). The windows in the scintillation counter were adjusted so that all of the $\left[{ }^{3} \mathrm{H}\right]$ was in one channel only. The amount of cross over of $\left[{ }^{14} \mathrm{C}\right]$ into this channel was then calculated using standards. Using this method, we were able to recover $100 \%$ of total cpm of $\left[{ }^{14} \mathrm{C}\right] 30 \mathrm{MG}$ and $\left[{ }^{3} \mathrm{H}\right]$ 3OMG mixed with rat blood.

Statistical analysis. All values are expressed as mean \pm standard deviation. Comparisons of portal venous and aortic 3OMG concentrations with different radiolabeling and with phloridzin were analyzed by oneway ANOVA. Comparisons of $\Delta \mathrm{C}_{30 \mathrm{MG}}$ with $\Delta \mathrm{C}_{\mathrm{L}-\text { glucose }}$ and $\Delta \mathrm{C}_{\mathrm{L}-\text { glucose }}$ with $\Delta \mathrm{C}_{\mathrm{L}-\text { glucose }}{ }^{*}$ were performed by two-tailed $t$ tests.

\section{Results}

\section{Validation studies.}

Validation of the use portal venous-aortic concentration gradients of $3 O M G$ and L-glucose to estimate the fraction of $3 O M G$ that is actively absorbed. In the following verification studies and derivations, we shall show that the fraction of total 3OMG absorption that occurs by active transport can be determined by measuring the portal venous-aortic blood concentration gradients $(\Delta C)$ of $30 M G$ and L-glucose without measuring portal venous blood flow.

The absorption rate $(\mathrm{J})$ of any substance across the intestine is equal to the concentration difference of the substance in the blood entering and exiting the intestine $(\Delta C)$ multiplied by the rate of blood flow through the intestine:

$J=\Delta C \times$ flow

If $\Delta \mathrm{C}_{\text {total }}$ and $\Delta \mathrm{C}_{\text {passive }}$ are the portal venous-aortic blood concentrations of substances that reflect total 3OMG transport and passive 3OMG transport, respectively, then

$$
\begin{aligned}
& J_{\text {total }}=\Delta C_{\text {total }} \times \text { flow } \\
& J_{\text {passive }}=\Delta C_{\text {passive }} \times \text { flow }
\end{aligned}
$$

Since total 3OMG absorption $\left(\mathrm{J}_{\text {total }}\right)$ is the sum of active transport $\left(\mathrm{J}_{\text {active }}\right)$ and passive absorption $\left(\mathrm{J}_{\text {passive }}\right)$, then

$J_{\text {active }}=J_{\text {total }}-J_{\text {passive }}$ 
Therefore, the fraction of total 3OMG absorption that occurs by active transport $\left(F_{\text {active }}\right)$ is calculated as follows

$F_{\text {active }}=J_{\text {active }} / J_{\text {total }}=\left(J_{\text {total }}-J_{\text {passive }}\right) / J_{\text {total }}$

Substituting Eqs. 2 and 3 into Eq. 4,

$F_{\text {active }}=\left(\Delta C_{\text {total }} \times\right.$ flow $-\Delta C_{\text {passive }} \times$ flow $)$

$\div\left(\Delta C_{\text {total }} \times\right.$ flow $)$.

If flow is the same for both measurements of $\Delta \mathrm{C}_{\text {total }}$ and $\Delta \mathrm{C}_{\text {passive }}$ as is automatically true by our method, where both are measured simultaneously, then equation 5 simplifies to

$F_{\text {active }}=\left(\Delta C_{\text {total }}-\Delta C_{\text {passive }}\right) / \Delta C_{\text {total }}$

In this study, we are measuring the fraction of 3OMG that is active. Therefore, the portal venous-aortic concentration gradient of 3OMG $\left(\Delta \mathrm{C}_{3 \mathrm{OMG}}\right)$ is substituted for $\Delta \mathrm{C}_{\text {total }}(15,30)$.

L-glucose is absorbed only passively and has the same permeability coefficient as D-glucose $(6,29,31,33)$. To use $\mathrm{L}$ glucose to estimate the passive component of 3OMG absorption, L-glucose must also have the same permeability as 3OMG. To test this assumption, we measured portal venous-aortic concentration gradients of $\mathrm{L}$-glucose $\left(\Delta \mathrm{C}_{\mathrm{L} \text {-glucose }}\right)$ after a 1-ml duodenal infusion of $100 \mathrm{mM} \mathrm{L}$-glucose with tracer amounts of $\left[{ }^{3} \mathrm{H}\right] \mathrm{L}$ glucose, and we also measured portal venous-aortic concentration gradients of 3OMG ( $\left.\Delta \mathrm{C}_{3 \mathrm{OMG}}\right)$ after a $1-\mathrm{ml}$ duodenal infusion of $100 \mathrm{mM} 30 \mathrm{OMG}$ with $0.5 \mathrm{mM}$ phloridzin and tracer amounts of $\left[{ }^{14} \mathrm{C}\right]$ 3OMG. Phloridzin at this concentration completely inhibits active transport of 3OMG and therefore allows one to measure the component of 3OMG absorption that occurs by diffusion $(1,34)$. Simultaneous aortic and portal venous blood samples were obtained 1 to $2 \mathrm{~min}$ after each of the above duodenal infusions and analyzed for $\left[{ }^{3} \mathrm{H}\right]$ or $\left[{ }^{14} \mathrm{C}\right]$. The concentrations of $3 \mathrm{OMG}\left(\mathrm{C}_{3 \mathrm{OMG}}\right)$ and $\mathrm{L}$-glucose $\left(\mathrm{C}_{\mathrm{L}-\text { glucose }}\right)$ in the aortic and portal venous blood were determined from the concentration of their radiolabeled tracer divided by the specific activity of the tracer in the infusate. Thus, the blood concentrations of $3 \mathrm{OMG}$ and L-glucose in nmoles/gm of blood were calculated as follows:

$C_{\text {3омG }}=\left(C_{\left[{ }^{14} \mathrm{C}\right] 30 \mathrm{gm}}\right) /\left(\mathrm{cpm}\right.$ of $\left[{ }^{14} \mathrm{C}\right]$ per $\mathrm{ml}$ of infusate

$\div$ nmole of 3 OMG per $\mathrm{ml}$ of infusate)

$C_{\mathrm{L}-\text { glucose }}=\left(C_{\left[{ }^{3} \mathrm{H}\right] \mathrm{L} \text {-glucose }}\right) /\left(\operatorname{cpm}\right.$ of $\left[{ }^{3} \mathrm{H}\right]$ per $\mathrm{ml}$ of infusate

$\div$ nmole of L-glucose per $\mathrm{ml}$ of infusate)

We found that the $\Delta \mathrm{C}_{\mathrm{L} \text {-glucose }}$ was $20 \pm 20$ nmoles/gm blood ( $n$ $=6$ ) and that the $\Delta \mathrm{C}_{3 \mathrm{OMG}}$ in the presence of phloridzin was $30 \pm 60 \mathrm{nmoles} / \mathrm{gm}$ blood $(n=6)$. Because there was not a significant difference $(P=0.72)$, our assumption appears to be valid and the passive permeabilities of $30 \mathrm{MG}$ and L-glucose are similar, and the portal venous-aortic concentration gradient of $\mathrm{L}$-glucose $\left(\Delta \mathrm{C}_{\mathrm{L} \text {-glucose }}\right)$ is equal to $\Delta \mathrm{C}_{\text {passive }}$.

To measure total and passive transport simultaneously, phloridzin could not be used because it would block active transport. In addition, some investigators claim that since phloridzin inhibits the increase in tight junction permeability caused by activation of sodium coupled transport, it would also block the component of passive transport due to solvent drag $(12,35)$. Thus, we shall show that tracer amounts of $\left[{ }^{3} \mathrm{H}\right]$ L-glucose with cold $3 \mathrm{OMG}$ in the duodenal infusate can be used to accurately deter- mine passive 3OMG absorption. We measured portal venousaortic concentration gradients of $\left[{ }^{3} \mathrm{H}\right] \mathrm{L}$-glucose in the presence of 3OMG after a 1-ml duodenal infusion of $100 \mathrm{mM} 30 \mathrm{MG}$ with tracer quantities of $\left[{ }^{3} \mathrm{H}\right] \mathrm{L}$-glucose. We determined the passive component of $30 \mathrm{OMG}$ absorption by dividing the concentration of $\left[{ }^{3} \mathrm{H}\right]$ L-glucose by the specific activity of $\left[{ }^{3} \mathrm{H}\right]$ per nmole of 3OMG. We defined this portal venous-aortic gradient as $\Delta \mathrm{C}_{\mathrm{L} \text {-glucose }}$ * with $\mathrm{C}_{\mathrm{L}-\text { glucose }}$ * defined as

$C_{\mathrm{L}-\text { glucose }} *=\left(C_{\left[{ }^{3} \mathrm{H}\right] \mathrm{L} \text {-glucose }}\right) /\left(\mathrm{cpm}\right.$ of $\left[{ }^{3} \mathrm{H}\right]$ per $\mathrm{ml}$ of infusate

$\div$ nmole of $30 \mathrm{MG}$ per $\mathrm{ml}$ of infusate).

We found that $\Delta \mathrm{C}_{\mathrm{L} \text {-glucose }}{ }^{*}$ was $20 \pm 10 \mathrm{nmoles} / \mathrm{gm}$ blood ( $n$ $=10$ ), which is the same as $\Delta \mathrm{C}_{\mathrm{L}-\text { glucose }}$. Debnam et al. used a similar technique in vitro to determine the passive absorption of D-glucose by using tracer concentrations of $\left[{ }^{14} \mathrm{C}\right] \mathrm{L}$-glucose in the presence of D-glucose (36).

In the above studies we have shown that in chronically catheterized rats,

$\Delta C_{3 \mathrm{OMG}}$ with phloridzin $=\Delta C_{\mathrm{L} \text {-glucose }}=\Delta C_{\mathrm{L} \text {-glucose }} *$

Thus, we conclude the following:

(a) Since $\Delta \mathrm{C}_{\mathrm{L}-\text { glucose }}=\Delta \mathrm{C}_{3 \mathrm{OMG}}$ with phloridzin, the permeability of L-glucose and $30 \mathrm{OMG}$ are the same.

(b) Since $\Delta \mathrm{C}_{\mathrm{L}-\text { glucose }}=\Delta \mathrm{C}_{\mathrm{L} \text {-glucose }}{ }^{*}$, measurements of the passive component of glucose absorption can be determined using tracer amounts of $\left[{ }^{3} \mathrm{H}\right] \mathrm{L}$-glucose with cold 3OMG.

(c) Since $\Delta \mathrm{C}_{\mathrm{L}-\text { glucose }} *=\Delta \mathrm{C}_{\mathrm{L}-\text { glucose }}$ and $\Delta \mathrm{C}_{3 \mathrm{OMG}}$ with phloridzin, an increase in tight junction permeability as a result of activation of sodium cotransport by $30 \mathrm{MG}$ is not significant. If increases in tight junction permeability as a result of activation of sodium cotransport contribute significantly to intestinal glucose absorption as proposed by some authors, then $\Delta \mathrm{C}_{\mathrm{L} \text {-glucose }} *$ (measured in the presence of 3OMG) should have been higher than $\Delta \mathrm{C}_{\mathrm{L} \text {-glucose }}$ (performed in the absence of an activator of sodium cotransport), and higher than $\Delta \mathrm{C}_{30 \mathrm{MG}}$ with phloridzin (performed in the presence of an inhibitor of sodium cotransport) $(12,37)$.

Because $\Delta \mathrm{C}_{3 \mathrm{OMG}}$ and $\Delta \mathrm{C}_{\mathrm{L} \text {-glucose }}{ }^{*}$ are measured simultaneously, the portal venous blood flow for each measurement is identical. Therefore, $\Delta \mathrm{C}_{3 \mathrm{OMG}}$ and $\Delta \mathrm{C}_{\mathrm{L} \text {-glucose }} *$ can be substituted for $\Delta \mathrm{C}_{\text {total }}$ and $\Delta \mathrm{C}_{\text {passive }}$ in Eq. 6 and

$F_{\text {active }}=\left(\Delta C_{3 \mathrm{OMG}}-\Delta C_{\mathrm{L}-\text { glucose }} *\right) / \Delta C_{3 \mathrm{OMG}}$

The effect of dilution of duodenal infusions by luminal contents. An advantage of studying intestinal absorption using acute methods is that the luminal concentration of substrates can be measured or controlled. In chronically catheterized rats, infusions of substrates into the intestine may be diluted by luminal contents already present and, therefore, we cannot determine the exact luminal concentration of a substrate after it is infused into the intestine. To determine the extent that a duodenal infusion is diluted by luminal contents, we used seven rats to measure the factor by which a $1 \mathrm{ml}$ bolus of $0.9 \% \mathrm{NaCl}$ containing tracer quantities of $\left[{ }^{14} \mathrm{C}\right]$ polyethylene glycol $(4 \mathrm{kD}, 0.1 \mu \mathrm{Ci} /$ $\mathrm{ml}$ ) was diluted. These rats (preoperative weight 305.7 \pm 25.2 ) had two duodenal catheters placed. The surgical procedure was the same as above, but catheters were not placed in the aorta or the portal vein. The first duodenal catheter was introduced as described above. A second catheter, consisting of a 12" intermittent infusion set (Abbott Laboratories, North Chicago, IL) 
Table I. $F_{\text {active }}$ at Different Luminal Concentrations of $3 O M G$

\begin{tabular}{|c|c|c|c|c|c|c|c|}
\hline \multirow[b]{2}{*}{ 3OMG infusion } & \multicolumn{3}{|c|}{$\mathrm{C}_{\text {зомG }}(\mathrm{nmoles} / \mathrm{gm}$ blood $)$} & \multicolumn{3}{|c|}{$\mathrm{C}_{\mathrm{L}-\text { glucose }}{ }^{*}(\mathrm{nmoles} / \mathrm{gm}$ blood $)$} & \multirow[b]{2}{*}{$\mathrm{F}_{\text {active }}(\%)$} \\
\hline & Portal vein & Aorta & $\Delta \mathrm{C} 30 \mathrm{MG}$ & Portal vein & Aorta & $\Delta$ CL-glucose* & \\
\hline $50 \mathrm{mM}(n=5)$ & $610 \pm 280$ & $90 \pm 70$ & $520 \pm 270$ & $40 \pm 20$ & $10 \pm 10$ & $30 \pm 10$ & $94 \pm 2$ \\
\hline $100 \mathrm{mM}(n=10)$ & $590 \pm 250$ & $170 \pm 110$ & $420 \pm 180$ & $70 \pm 50$ & $40 \pm 40$ & $20 \pm 10$ & $95 \pm 1$ \\
\hline $200 \mathrm{mM}(n=9)$ & $950 \pm 750$ & $200 \pm 90$ & $760 \pm 690$ & $150 \pm 60$ & $120 \pm 60$ & $30 \pm 30$ & $96 \pm 1$ \\
\hline $400 \mathrm{mM}(n=7)$ & $1170 \pm 640$ & $240 \pm 70$ & $930 \pm 610$ & $120 \pm 40$ & $60 \pm 10$ & $50 \pm 30$ & $94 \pm 2$ \\
\hline
\end{tabular}

Simultaneous portal venous and aortic blood samples were drawn after a $1 \mathrm{ml}$ duodenal infusion of 50, 100, 200, or 400 mM 30MG containing tracer quantities of $\left[{ }^{3} \mathrm{H}\right] \mathrm{L}$-glucose and $\left[{ }^{14} \mathrm{C}\right] 3 \mathrm{OMG}$. $\mathrm{C}_{30 \mathrm{MG}}$ is the blood concentration of $3 \mathrm{OMG}$. $\mathrm{C}_{\mathrm{L}-\text { glucose }} *$ is the blood concentration of $\mathrm{L}$-glucose in the presence of 3OMG. $\Delta \mathrm{C}_{\mathrm{OMG}}$ and $\Delta \mathrm{C}_{\mathrm{L}-\text { glucose }}{ }^{*}$ are the portal venous-aortic blood concentration gradients of $30 \mathrm{OMG}$ and $\mathrm{L}$-glucose. $\mathrm{F}_{\text {active }}(\%)$ is the fraction of glucose absorption that occurs by active transport and is equal to $\left(\Delta \mathrm{C}_{30 \mathrm{MG}}-\Delta \mathrm{C}_{\mathrm{L} \text {-glucose }}{ }^{*}\right) / \Delta \mathrm{C}_{3 \mathrm{OMG}} \times 100 \%$. Results are mean $\pm \mathrm{SD}$.

from which the needle had been removed was inserted $1 \mathrm{~cm}$ distal to the initial duodenal catheter through a hole made in the intestine using an 18-gauge needle. This catheter was held in place with a purse string suture through the serosa using 5O silk suture.

Polyethylene glycol 4000 (PEG) was used in these experiments because most studies have found it not to be significantly absorbed by the rat small intestine (e.g., 38, 39, 40). Therefore, any decrease in the concentration of $\left[{ }^{14} \mathrm{C}\right] \mathrm{PEG}$ is secondary to dilution from duodenal contents. One study claims that PEG may be absorbed by the intestine, but the absorption rate in that study was very slow, and was determined over a period of hours (7). In contrast, our experiment was carried out over a period of $\sim 1 \mathrm{~min}$. If any PEG was actually absorbed, then the amount of dilution that we calculated may be slightly overestimated.

At least $4 \mathrm{~d}$ postoperative, $1.0 \mathrm{ml}$ of $0.9 \% \mathrm{NaCl}$ containing tracer amounts of $\left[{ }^{14} \mathrm{C}\right]$ PEG was infused into the proximal duodenal catheter. After the infusion was complete, luminal fluid was aspirated from the distal catheter. $0.05 \mathrm{ml}$ aliquots of the aspirated fluid were mixed with $5 \mathrm{ml}$ of scintillation fluid. The samples were then analyzed for $\left[{ }^{14} \mathrm{C}\right]$ concentrations and compared to standards from the infusate. We calculated the decrease in the concentration of PEG of the fluid aspirated from the duodenum as a percentage of the concentration of PEG that was infused. Dilution of a $1.0 \mathrm{ml}$ duodenal infusion proved to be $15.7 \pm 12.4 \%$ (mean $\pm \mathrm{SD})$.

\section{The fraction of $30 M G$ absorption that occurs by active transport}

The portal venous and aortic blood concentrations of the total and passive components of $30 \mathrm{MG}$ were measured after a duodenal infusion of cold $30 \mathrm{MG}$ ranging in concentration from 50 to $400 \mathrm{mM}$ and containing tracer quantities of $\left[{ }^{14} \mathrm{C}\right] 3 \mathrm{OMG}$ and $\left[{ }^{3} \mathrm{H}\right]$ L-glucose. These concentrations were selected because previous studies using acute methods suggested that in this concentration range a significant fraction of luminal glucose would be passively absorbed (1-4). The fraction of 3OMG absorption that resulted from active transport proved to be $94 \%$ or more at all four luminal concentrations tested $(50,100,200$, and $400 \mathrm{mM}$ : Table I).

To test whether the relatively high fraction of active transport determined by our method was secondary to differences in the absorption rates of the different radiolabeled analogues of glucose, we also reversed the radiolabeling so that the fraction of active transport was measured after a duodenal infusion of
$100 \mathrm{mM}$ cold 3OMG with tracer amounts of $\left[{ }^{3} \mathrm{H}\right] 3 \mathrm{OMG}$ and $\left[{ }^{14} \mathrm{C}\right] \mathrm{L}$-glucose. The fraction of 3OMG absorption determined to be active after this infusion was not different when compared to the duodenal infusion containing $100 \mathrm{mM}$ cold $30 \mathrm{OMG}$ with tracer quantities of $\left[{ }^{14} \mathrm{C}\right] 3 \mathrm{OMG}$ and $\left[{ }^{3} \mathrm{H}\right] \mathrm{L}$-glucose (Table II). Therefore, a possible difference in the absorption rates of $\left[{ }^{3} \mathrm{H}\right]$ and $\left[{ }^{14} \mathrm{C}\right]$ radiolabeled isotopes did not account for this high rate of active transport.

An inhibitor of active glucose transport, phloridzin, was added to the duodenal infusate as another method of determining the fraction of active transport. When $0.5 \mathrm{mM}$ phloridzin was added to the duodenal infusion containing $100 \mathrm{mM}$ 3OMG with radiolabeled 3OMG and L-glucose, the portal venous-aortic concentration gradient of $30 \mathrm{OG}$ was significantly decreased, and active transport decreased to $6 \pm 13 \%$ of total 3 OMG transport (Table II).

\section{Discussion}

The relative amounts of active and passive 30MG absorption were measured in unrestrained, unanesthetized rats that were feeding and gaining weight at least $4 \mathrm{~d}$ postoperative. The fraction of luminal 3OMG that is absorbed by active transport was determined by simultaneously measuring the portal venous-aortic blood concentration gradients of $30 M G$ and L-glucose after a duodenal infusion of $30 \mathrm{MG}$ containing isotopes of $3 \mathrm{OMG}$ and L-glucose in tracer quantities. Using this method, we showed that $\sim 94 \%$ of luminal $30 \mathrm{OMG}$ is actively absorbed by the intestine even at concentrations as high as $400 \mathrm{M}$. As expected, the addition of phloridzin, an inhibitor of active glucose transport, blocked virtually all active transport and thus supported our conclusions. Thus, passive transport contributes little to total glucose absorption under physiological conditions.

Our method offers many advantages over previous methods. Each measurement of the relative contributions of passive and active transport was performed in the same rat at the same time after the same duodenal infusion, thereby eliminating inter-rat and inter-experiment variability. Intestinal function can be studied in unanesthetized, unrestrained animals in a nonfasting state. By measuring the ratios of $\Delta \mathrm{C}_{30 \mathrm{MG}}$ and $\Delta \mathrm{C}_{\mathrm{L}-\text { glucose }} *$ simultaneously, the resistance of the unstirred water layer, intestinal blood flow, dilution of intestinal contents, and length of intestine exposed is automatically the same for both.

$\mathrm{C}_{3 \mathrm{OMG}}$ and $\mathrm{C}_{\mathrm{L} \text {-glucose }} *$ in portal venous and aortic blood 
Table II. The Effects of Phloridzin and Reversing the Radiolabeling on $F_{\text {active }}$

\begin{tabular}{|c|c|c|c|c|c|c|c|}
\hline \multirow[b]{2}{*}{ Duodenal infusion } & \multicolumn{3}{|c|}{$\mathrm{C}_{\text {зом⿰ }}$ (nmoles/gm) } & \multicolumn{3}{|c|}{$\mathrm{C}_{\mathrm{L} \text {-gluocose }}{ }^{*}(\mathrm{nmoles} / \mathrm{gm})$} & \multirow[b]{2}{*}{$\mathrm{F}_{\text {ective }}(\%)$} \\
\hline & Portal vein & Aorta & $\Delta \mathrm{C} 3 \mathrm{OMG}$ & Portal vein & Aorta & $\Delta$ CL-glucose* & \\
\hline \multicolumn{8}{|l|}{$\left[{ }^{3} \mathrm{H}\right] \mathrm{L}$-glucose } \\
\hline $\begin{array}{l}{\left[{ }^{14} \mathrm{C}\right] \text { 3OMG }(n=10)} \\
{\left[{ }^{14} \mathrm{C}\right] \text { L-glucose }}\end{array}$ & $590 \pm 250$ & $170 \pm 110$ & $420 \pm 190$ & $70 \pm 50$ & $40 \pm 40$ & $20 \pm 10$ & $95 \pm 1$ \\
\hline $\begin{array}{l}{\left[{ }^{3} \mathrm{H}\right] \text { 3OMG }(n=7)} \\
{\left[{ }^{3} \mathrm{H}\right] \text { L-glucose }}\end{array}$ & $720 \pm 260$ & $160 \pm 70$ & $560 \pm 260$ & $40 \pm 30$ & $20 \pm 20$ & $20 \pm 20$ & $96 \pm 3$ \\
\hline $\begin{array}{l}{\left[{ }^{14} \mathrm{C}\right] 3 \mathrm{OMG}(n=6)} \\
0.5 \mathrm{mM} \text { phloridzin }\end{array}$ & $90 \pm 140^{\ddagger}$ & $70 \pm 90$ & $30 \pm 50^{\ddagger}$ & $130 \pm 220$ & $90 \pm 160$ & $30 \pm 60$ & $6 \pm 13^{\ddagger}$ \\
\hline
\end{tabular}

Simultaneous portal venous and aortic blood samples were drawn after a $1-\mathrm{ml}$ duodenal infusion of $100 \mathrm{mM} 30 \mathrm{MG}$ with and without $0.5 \mathrm{mM}$ phloridzin and containing tracer quantities of $\left[{ }^{3} \mathrm{H}\right] \mathrm{L}$-glucose and $\left[{ }^{14} \mathrm{C}\right] 3 \mathrm{OMG}$, or after a 1-ml duodenal infusion of $100 \mathrm{mM} 30 \mathrm{MG}$ with the isotopes reversed. $\mathrm{C}_{30 \mathrm{MG}}$ is the blood concentration of $30 \mathrm{MG}$. $\mathrm{C}_{\mathrm{L}-\text { glucose }}{ }^{*}$ is the blood concentration of $\mathrm{L}$-glucose in the presence of $30 \mathrm{MG}$. $\Delta \mathrm{C}_{30 \mathrm{MG}}$ and $\Delta \mathrm{C}_{\mathrm{L}-\text { glucose }}{ }^{*}$ are the portal venous-aortic blood concentration gradients of $30 \mathrm{MG}$ and L-glucose. $\mathrm{F}_{\text {active }}(\%)$ is the fraction of glucose absorption that occurs by active transport and is equal to $\left(\Delta \mathrm{C}_{3 \text { омG }}-\Delta \mathrm{C}_{\mathrm{L} \text {-glucose }}{ }^{*}\right) / \Delta \mathrm{C}_{3 \mathrm{OMG}} \times 100 \%$. Results are mean $\pm \mathrm{SD}$. ${ }^{\ddagger} P<0.001$ vs other groups by oneway ANOVA.

showed relatively wide variability among the animals. This may be due to differences in portal venous blood flow or incomplete mixing of blood from different regions of the intestine within the portal vein. Because measurements of $\mathrm{C}_{\mathrm{L} \text {-glucose }} *$ and $\mathrm{C}_{3 \mathrm{OMG}}$ were performed simultaneously, however, all of these factors would affect both analogues equally. Therefore, the calculations of the fraction of active glucose transport had very little variability.

We were able to verify the few assumptions that our model requires. First, we showed that the measurement of passive absorption using tracer quantities of $\left[{ }^{3} \mathrm{H}\right]$ L-glucose in cold $3 \mathrm{OMG}$ is the same as using tracer quantities of $\left[{ }^{3} \mathrm{H}\right] \mathrm{L}$-glucose in cold L-glucose. Therefore, calculating $\mathrm{C}_{\mathrm{L} \text {-glucose }}{ }^{*}$ from portal venous and aortic concentrations of $\left[{ }^{3} \mathrm{H}\right] \mathrm{L}$-glucose in the presence of $30 \mathrm{MG}$ is valid. Second, we showed that the fraction of active transport was not affected by the $\left[{ }^{3} \mathrm{H}\right]$ and $\left[{ }^{14} \mathrm{C}\right]$ radiolabeling of the glucose analogues. Finally, a $1.0 \mathrm{ml}$ duodenal infusion was diluted by only $15 \%$. Therefore, the high fraction of active transport of glucose was not due to low luminal concentrations of $30 \mathrm{MG}$ due to significant dilution of glucose in the duodenal infusion.

In this study, we determined the fraction of 30MG that is absorbed by active transport in the intestine by measuring the rate of its appearance in the portal vein. In contrast, most previous studies of intestinal glucose absorption using techniques such as perfusion of an isolate intestinal loop or everted sleeves measured the rate of disappearance of glucose from the lumen or mucosal surface $(2,4-8,12-14)$. Because $30 \mathrm{MG}$ is not metabolized or accumulated by the intestine, the rate of appearance of $30 \mathrm{MG}$ into the portal vein is equal to the rate of disappearance from the intestinal lumen (9). Since D-glucose is metabolized by the intestine, the rate of appearance of D-glucose into the portal vein is less than is actually absorbed by the intestine $(30,41)$.

The results of this study imply that the most D-glucose absorption also occurs by active transport. 3OMG is actively transported at the brush border membrane by the major sodiumdependent transporter that transports D-glucose. Fedorak et al. showed that the $K_{\mathrm{m}}$ for D-glucose and 3OMG are similar but that the $V_{\max }$ was $\sim 30 \%$ less (15). Thomson et al. showed that the rate of $30 \mathrm{MG}$ uptake in rats was $40 \%$ less than for Dglucose (33). In addition, L-glucose accurately estimates the passive absorption of D-glucose $(6,29,31,33)$. Thus, the fraction of D-glucose absorption that occurs by active transport is probably comparable to $30 \mathrm{MG}$.

The results of this study are in conflict with those studies of intestinal glucose absorption that claimed that passive absorption begins to exceed active transport at luminal concentration of glucose as low as $35-60 \mathrm{mM}(1-4)$. These studies used methods in which the intestine had been acutely manipulated surgically either in vivo or in vitro. Our study is consistent with a study in humans in vivo by Fine et al., who showed that $95 \%$ of glucose was actively absorbed at luminal glucose concentrations of $120 \mathrm{mM}$ under conditions which avoid the effects of anesthesia and acute surgical bowel manipulation (42). We speculate that the explanation for the lower fraction of active transport in those studies that conflict with our results is the adverse effects of surgical bowel manipulation and anesthesia on intestinal transport. In previous studies in rats by Kimura et al., there was a faster rate of increase in portal venous and aortic blood concentrations of glucose after a gastric infusion of glucose under chronic conditions in comparison with measurements immediately postoperative (28). In the accompanying paper, we show that active transport of glucose by the intestine is decreased $90 \%$ immediately after laparotomy while passive absorption remains unaffected (32). The possible mechanisms for this decrease in active transport of glucose are discussed in the accompanying paper.

Pappenheimer, Madara, and colleagues believe that the phenomenon of solvent drag, by which luminal solutes are passively absorbed by convection along with water, is the mechanism that enables the intestine to absorb large amounts of glucose despite low rates of active transport $(5,7,12,35,43)$. These investigators claim that paracellular transport secondary to solvent drag is enhanced by activation of sodium-coupled transport which causes dilation of paracellular channels $(5,7,12,35)$. Since our studies were performed in the presence of $30 \mathrm{MG}$, an activator of the sodium-coupled transport, paracellular channels should have been dilated and passive transport maximized (12, 37). Despite activation of sodium-coupled transport, however, 
all passive mechanisms combined (including diffusion and solvent drag) were responsible for only $6 \%$ of $30 \mathrm{MG}$ absorption at a luminal concentration of $400 \mathrm{mM}$. In addition, the portal venous-aortic concentration gradient of $\mathrm{L}$-glucose $\left(\Delta \mathrm{C}_{\mathrm{L}-\text { glucose }} *\right)$ was not significantly different in the presence or absence of phloridzin ( $20 \pm 10 \mathrm{nmoles} / \mathrm{gm}$ without phloridzin vs $30 \pm 60$ nmoles/gm with phloridzin, Table II). Since phloridzin inhibits the increase in tight junction permeability caused by 3OMG, if there is a significant increase in tight junction permeability caused by $30 \mathrm{MG}$ then $\Delta \mathrm{C}_{\mathrm{L} \text {-glucose }}{ }^{*}$ measured with phloridzin should have been less than when phloridzin was not present (12). This lack of effect of phloridzin on permeability suggests that, under physiologic conditions, alteration of tight junction permeability does not contribute significantly to intestinal glucose absorption.

In addition, the fact that the portal venous-concentration gradients of 3OMG with phloridzin, L-glucose in the presence of L-glucose alone, and L-glucose in the presence of $30 \mathrm{MG}$ ( $\Delta \mathrm{C}_{30 \mathrm{MG}}$ with phloridzin, $\Delta \mathrm{C}_{\mathrm{L}-\text { glucose }}$, and $\Delta \mathrm{C}_{\mathrm{L}-\text { glucose }}{ }^{*}$, respectively as described in the results section) were not significantly different indicates that solvent drag may not contribute significantly to glucose absorption under physiologic conditions. $\Delta \mathrm{C}_{\mathrm{L}-\text { glucose }}{ }^{*}$ measured passive absorption of $\left[{ }^{3} \mathrm{H}\right] \mathrm{L}$-glucose in the presence of 3OMG. Under this condition the absorption of the $\left[{ }^{3} \mathrm{H}\right]$ L-glucose tracer should have been maximized $(7,12)$. Since $\Delta \mathrm{C}_{\mathrm{L} \text {-glucose }}{ }^{*}$ was not different from $\Delta \mathrm{C}_{\mathrm{L} \text {-glucose }}$ in which measurements of passive absorption were performed with Lglucose only, 3OMG did not significantly increase the permeability of the intestine to L-glucose. Furthermore, phloridzin, an inhibitor the sodium-coupled glucose transporter and its effect on tight junction permeability, did not change passive permeability as shown by the fact that $\Delta \mathrm{C}_{\mathrm{L} \text {-glucose }}{ }^{*}$ was not different from $\Delta \mathbf{C}_{30 \mathrm{MG}}$ with phloridzin. This is in agreement with the study in humans by Fine et al. showing that intestinal permeability to mannitol and L-xylose was not increased in the presence of D-glucose (42).

In our chronically catheterized rat model, dilution of our duodenal infusion by intestinal contents may decrease the luminal concentrations of $30 \mathrm{MG}$ and L-glucose. However, we found that infusions into the duodenum were only diluted $15 \%$ (see Results). This dilution factor does not significantly change our results.

Using our method, we cannot accurately determine the length of intestine exposed to the infused substrate. Since we measured the portal venous-aortic concentration gradients of $\mathrm{L}$ glucose and 3OMG simultaneously after a single duodenal bolus, the same length of intestine was exposed to both L-glucose and 3OMG. Regardless of how much intestine was exposed to the infusion, the relative proportion of active and passive absorption for intestinal glucose absorption would not change.

We conclude that most luminal 3OMG is actively absorbed by the intestine under physiologic conditions. Since active transport greatly exceeds passive transport including both diffusion and solvent drag, it is apparent that solvent drag contributes minimally to glucose absorption in vivo under conditions which avoid the effects of acute surgical bowel manipulation and anesthesia. These results are similar to results in humans performed without the effects of laparotomy and anesthesia (42).

\section{References}

1. Debnam, E. S., and R. J. Levin. 1975. An experimental method of identifying and quantifying the active transfer electrogenic component from the diffu- sive component during sugar absorption measured in vivo. J. Physiol. 246:181196.

2. Murakami, E., M. Saito, and M. Suda. 1977. Contribution of diffusive pathway in intestinal absorption of glucose in rat under normal feeding conditions. Specialia. 15:1469-1470.

3. Westergaard, H. 1989. Insulin modulates rat intestinal glucose transport: effect of hypoinsulinemia and hyperinsulinemia. Am. J. Physiol. 256:G911-G918.

4. Cheeseman, C. I. and B. Harley. 1991. Adaptation of glucose transport across rat enterocyte basolateral membrane in response to altered dietary carbohydrate intake. J. Physiol. (Lond.). 437:563-575.

5. Madara, J. L., and J. R. Pappenheimer. 1987. Structural basis for physiological regulation of paracellular pathways in intestinal epithelia. J. Membr. Biol. 100:149-164.

6. Meddings, J. B., and H. Westergaard. 1989. Intestinal glucose transport using perfused rat jejunum in vivo: model analysis and derivation of corrected kinetic constants. Clin. Sci. 76:403-413.

7. Pappenheimer, J. R., and K. Z. Reiss. 1987. Contribution of solvent drag through intercellular junctions to absorption of nutrients by the small intestine of the rat. J. Membr. Biol. 100:123-136.

8. Westergaard, H., K. H. Holtermuller, and J. M. Dietschy. 1986. Measurement of resistance of barriers to solute transport in vivo in rat jejunum. Am. J. Physiol. 250:G727-G735.

9. Boyd, C. A. R., and D. S. Parsons. 1978. Effects of vascular perfusion on the accumulation, distribution and transfer of 3-O-methyl-D-glucose within and across the small intestine. J. Physiol. 274:17-36.

10. Mokuda, O., Y. Sakamoto, T. Ikeda, and H. Mashiba. 1989. Direct inhibitory effect of high glucose in mesenteric artery on glucose absorption from isolated perfused rat intestine. Ann. Nutr. Metab. 33:330-332.

11. Porteous, J. W., J. D. Hutchison, and V. Undrill. 1984. The luminallyand vascularly-perfused small intestine as an experimental system for the study of translocation and metabolism. Proc. Nutr. Soc. 43:141-160.

12. Atisook, K., S. Carlson, and J. L. Madara. 1990. Effects of phlorizin and sodium on glucose-elicited alterations of cell junctions in intestinal epithelia. Am. J. Physiol. 258:C77-C85.

13. Buddington, R. K., and J. Diamond. 1992. Ontogenic development of nutrient transporters in cat intestine. Am. J. Physiol. 263:G605-G616.

14. Karasov, W. H., and E. S. Debnam. 1987. Rapid adaptation of intestinal glucose transport: a brush-border or basolateral phenomenon? Am. J. Physiol. 253:G54-G61.

15. Fedorak, R. N., A. B. R. Thomson, and V. M. Porter. 1991. Adaptation of intestinal glucose transport in rats with diabetes mellitus occurs independent of hyperphagia. Can. J. Physiol. Pharmacol. 69:1143-1148.

16. Meddings, J. B., D. DeSouza, M. Goel, and S. Thiesen. 1990. Glucose transport and microvillus membrane physical properties along the crypt-villus axis of the rabbit. J. Clin. Invest. 85:1099-1107.

17. Moe, A. J., and M. J. Jackson. 1987. Isolation and characterization of brush border membrane vesicles from pig small intestine. Comp. Biochem. Physiol. A. 88:511-517.

18. Stevens, B. R., J. D. Kaunitz, and E. M. Wright. 1984. Intestinal transport of amino acids and sugars: advances using membrane vesicles. Ann. Rev. Physiol. 46:417-433.

19. McRoberts, J. A., R. Aranda, N. Riley, and H. Kang. 1990. Insulin regulates the paracellular permeability of cultured intestinal epithelial cell monolayers. J. Clin. Invest. 85:1127-1134.

20. Anderson, B. W., A. S. Levine, D. G. Levitt, J. M. Kneip, and M. D. Levitt. 1988. Physiological measurement of luminal stirring in perfused rat jejunum. Am. J. Physiol. 254:G843-G848.

21. Sjovall, H., I. Hagman, and H. Abrahamsson. 1990. Relationship between interdigestive duodenal motility and fluid transport in humans. Am. J. Physiol. 259:G348-G354.

22. Gumbleton, M., P. J. Nicholls, and G. Taylor. 1990. Differential influence of laboratory anaesthetic regimens upon renal and hepatosplanchnic haemodynamics in the rat. J. Pharm. Pharmacol. 42:693-697.

23. Hakim, A. A., and N. Lifson. 1969. Effects of pressure on water and solute transport by dog intestinal mucosa in vitro. Am. J. Physiol. 216:276-284.

24. Hollander, D., S. Koyama, V. Dadufalza, D. Q. Tran, P. Krugliak, T. Ma, and K. Y. Ling. 1989. Polyethylene glycol 900 permeability of rat intestinal and colonic segments in vivo and brush border membrane vesicles in vitro. J. Lab. Clin. Med. 113:505-15.

25. Karbach, U., and R. Wanitschke. 1984. Influence of serosal hydrostatic pressure on net water and electrolyte transport across the isolated rat colonic mucosa exposed to different secretagogues. Naunyn-Schmiedeberg's Arch. Pharmacol. 327:336-341.

26. Rich-Denson, C., and R. E. Kimura. 1988. In vivo evidence that most of the intraluminally absorbed glucose is absorbed intact into the portal vein and not metabolized to lactate. Biochem. J. 254:931-934.

27. Gumbleton, M., P. J. Nicholls, and G. Taylor. 1990. Differential effects 
of anesthetic regimens on gentamicin pharmacokinetics in the rat: a comparison with chronically catheterized conscious animals. Pharm. Res. 7:41-45.

28. Kimura, R. E., T. R. LaPine, and W. M. Gooch III. 1988. Portal venous and aortic glucose and lactate changes in a chronically catheterized rat. Pediatr Res. 23:235-240.

29. Boyd, C. A. R., and D. S. Parsons. 1979. Movements of monsaccharides between blood and tissues of vascularly perfused small intestine. J. Physiol 287:271-291.

30. Csaky, T. Z., and M. Thale. 1960. Effect of ionic environment on intestina sugar transport. J. Physiol. Lond. 151:59-65.

31. Wilson, T. H., and B. R. Landau. 1960. Specificity of sugar transport by the intestine of the hamster. Am. J. Physiol. 198:99-102.

32. Uhing, M. R., and R. E. Kimura. 1995. The effect of surgical bowe manipulation and anesthesia on intestinal glucose absorption in rats. J. Clin. Invest. 95:2790-2798.

33. Thomson, A. B. R., C. A. Hotke, and W. M. Weinstein. 1982. Comparison of kinetic constants of hexose uptake in four animal species and man. Comp. Biochem. Physiol. 72A:225-236.

34. Fedorak, R. N., E. B. Chang, J. L. Madara, and M. Field. 1987. Intestina adaptation to diabetes. Altered Na-dependent nutrient absorption in streptozocintreated chronically diabetic rats. J. Clin. Invest. 79:1571-1578.

35. Pappenheimer, J. R. 1993. On the coupling of membrane digestion with intestinal absorption of sugars and amino acids. Am. J. Physiol. 265:G409-G417.
36. Debnam, E. S., W. H. Karasov, and C. S. Thompson. 1988. Nutrient uptake by rat enterocytes during diabetes mellitus; evidence for an increased sodium electrochemical gradient. J. Physiol. Lond. 397:503-512.

37. Pappenheimer, J. R. 1987. Physiological regulation of transepithelial impedance in the intestinal mucosa of rats and hamsters. J. Membr. Biol. 100:137148.

38. Miller, D. L., and H. P. Schedl. 1970. Total recovery studies of nonabsorbable indicators in the rat small intestine. Gastroenterology 58:40-46.

39. French, A. B., I. F. Brown, C. J. Good, and G. M. McLeod. 1968. Comparison of phenol red and polyethylene glycol as nonabsorbable markers for the study of intestinal absorption in humans. Am. J. Dig. Dis. 13:558-564.

40. Schedl, H. P. 1966. Use of polyethylene glycol and phenol red as unabsorbed indicators for intestinal absorption studies in man. Gut. 7:159-163.

41. Kimura, R. E., G. Thulin, and J. B. Warshaw. 1984. The effect of ketone bodies and fatty acid on intestinal glucose metabolism during development. Pediatr. Res. 18:575-579.

42. Fine, K. D., A. C. Santa, J. L. Porter, and J. S. Fordtran. 1993. Effect of D-glucose on intestinal permeability and its passive absorption in human small intestine in vivo. Gastroenterology. 105:1117-1125.

43. Nellans, H. N. 1991. Mechanisms of peptide and protein absorption: paracellular intestinal transport: modulation of absorption. Adv. Drug Delivery Rev. 7:339-364. 